\title{
EL PATRIOTISMO. UN CONCEPTO DE ACCIÓN Y DE REACCIÓN. RESPONSABILIDAD DE ACTUAR EN TIEMPOS DE CRISIS (1808-1812)
}

\section{Esteban Gómez Gaitán ${ }^{1}$}

\begin{abstract}
Resumen
La investigación empleó metodológicamente, la historia conceptual comparada relacionada con la ideopraxias y los saberes jurídicos de los actores políticos en el espacio temporal planteado. El objetivo fue indagar el concepto de patriotismo, sus diversas posibilidades de sentido no desde sí mismo, sino como era empleado por los súbditos españoles, diferenciados, entre ciudadanos/vecinos de Madrid (autoridades constituidas) y juntistas. De los resultados obtenidos se observó que, entre la acción/ reacción de unos y otros, el concepto adquiría nuevos significados, en la recomposición de la lealtad jurada del vasallo con su monarca, transformándose en las obligaciones ciudadanas a los mandatos legales.
\end{abstract}

Palabras clave: Necesidad; Responsabilidad; Acción; Reacción; Fidelidad.

\section{CONOCIMIENTO ACUMULADO DEL CONCEPTO DE PATRIOTISM}

En la época contemporánea, a partir de la primera guerra mundial, los estudiosos en campos como la psicología, la educación, la literatura y la historia han efectuado investigaciones acerca del patriotismo desde un sentido negativo, identificándole como: pseudo-patriotismo o chauvinismo. Tal es el caso de: Daniel Bar-Tal, quien lo identificó como una creencia fundamental de pertenencia al grupo. Esta adhesión se reflejaba en las creencias y emociones de los individuos. No obstante que el patriotismo en su forma esencial fuera genuino, podía tener consecuencias negativas cuando se le añadían creencias con contenidos específicos. ${ }^{2}$ Por su parte, Karsten, Peter y Shafer, Boyd C., basaron sus estudios desde la literatura, en sus obras enaltecieron las acciones del patriota junto con los himnos nacionales y las banderas, como parte de los aspectos más importantes de su propia identidad. ${ }^{3}$ Fiske, Susan T. y Taylor, Shelley E., analizaron el patriotismo a manera de una red semántica de

\footnotetext{
${ }^{1}$ Posdoctoral, becado por el Consejo de Ciencia y Tecnología, adscrito al programa de Maestría en Historia. Estudios Interdisciplinarios, División de Ciencias Sociales y Humanidades de la Universidad de Guanajuato, México. E-mail: esteban_gaitan@hotmail.com

2 BAR-TAL, Daniel, (1994) “Patriotismo como creencia fundamental de la pertenencia al grupo", Revista Psicología Política, no. 8, 63-85.

${ }^{3}$ KARSTEN, Peter, (1978). Patriots-heroes in England and America: Political symbolism and changing values over three centuries, Madison: University of Wisconsin Press, 1-256. SHAFER, Boyd C., (1972). Faces of nationalism: New realities and old myths, New York: Harcourt Brace Jovanovich, 1-535.
} 
significados e implicaciones asociadas. ${ }^{4}$

En cuanto al patriotismo constitucional, Jürgen Habermas y Hans Georg Gadamer, han abordado el tema: El primero, de manera cronológica, tomó como referencia el desarrollo del nacionalismo europeo y de sus influencias sociales, entró en su entorno histórico desde su gestación al terminar la segunda guerra mundial, en esa desconexión de identidad cultural, en donde el nacionalismo se disociaba del Estado y dio lugar a la identificación de la población con aquello digno de conservarse. ${ }^{5}$ En cambio, el segundo de los autores, difería de Habermas, en la interpretación del vocablo. Para el autor de "Verdad y Método", no hay comprensión fuera del marco histórico. Por lo tanto, el término, es una subordinación a un sistema de relaciones jurídicas. ${ }^{6}$

En la línea de la historia conceptual, diversos estudiosos han analizado el vocablo Patria. Gabriel de Meglio, indagó el término, sus mutaciones semánticas, en el contexto de la revolución rioplatense. ${ }^{7}$ David Velázquez, profundizó en su obra el concepto Patria en el espacio peruano entre 1730 a 1866, en donde, mostraba una tendencia de desvinculación en la aplicación del concepto hacia una diversidad de organizaciones políticas. ${ }^{8}$ Isabel Ma. Povea Moreno, averiguó diferentes significados y usos entre absolutistas y liberales durante el interregno gaditano en el Perú. ${ }^{9}$ En cambio, Gabriel Entin, exploró en una dimensión constitutiva de identidad americana: en la identificación de las Américas como una patria común, en una construcción, social, histórica y lingüística. ${ }^{10}$

A su vez, Álvaro Acevedo Tarazona y Jorge Luis Cárdenas Naranjo, en su artículo "Resignificar el pasado para ser libres: resemantización ideológica de los conceptos colonia y patria, 1790-1830", reflexionaron acerca de la relación inter conceptual de los términos y diferencias de colonia y patria. Para ello, retomaron la reflexión iniciada por Annick Lempérière sobre la cuestión colonial, los aportes historiográficos efectuados sobre el concepto colonia. Utilizaron como fuente primaria de análisis el Papel Periódico de Santa Fe, en la Nueva Granada, después de estallar su revolución independentista, a fin de entretejer los vocablos en la configuración del campo semántico de las revoluciones liberales americanas. ${ }^{11}$

\footnotetext{
${ }^{4}$ FISKE, Susan T. \& TAYLOR, Sheller E., Social Cognition, (New York: Random House, 1984), 1-97.

${ }^{5}$ HABERMAS, Jürgen, (2007). Identidades nacionales y postnacionales, Madrid, Tecnos, 101-102.

${ }^{6}$ GADAMER, Hans Georg, (1998). Verdad y Método. Fundamentos de una Hermenéutica filosófica. Salamanca, Sígueme.

${ }^{7}$ DI MEGLIO, Gabriel, “Patria”, en GOLDMAN, Noemí (ed.), (2008). Lenguaje y revolución: Conceptos políticos clave en el Río de la Plata, 1780-1850, Buenos Aíres, Prometeo, Libros, 115-130.

${ }^{8}$ VELÁSQUEZ SILVA, David Víctor, tesis de licenciatura, (2010). Mutaciones del concepto patria, Perú, 1730-1866, Lima, Universidad Mayor de San Marcos, 1-177.

9 POVEA MORENO, Isabel Ma., (2012). "Una encrucijada conceptual en el marco de las independencias: La voz Patria, Perú, 1808-1814”, Revista Chronica Nova, 38, 59-80.

${ }^{10}$ ENTIN, GABRIEL, El patriotismo americano en el siglo XVIII: ambigüedades de un discurso político hispánico, en HÉBRARD Verónique \& VERDO Geneviéve, (eds.), Las independencias hispanoamericanas. Un objeto de Historia, (2017). Volumen 137, Madrid, Casa de Velázquez, 19-33.

${ }^{11}$ ACEVEDO TARAZONA, Álvaro, CÁRDENAS NARANJO, Jorge Luís (2017). Resignificar el pasado para ser libres: resemantización ideológica de los conceptos colonia y patria, 1790-1830. Revista Psicoespacios, Vol. 11, N. 19, pp.249-268 obtenido de la información: https://doi.org/10.25057/issn.2145-2776, el día 20 de septiembre de 2017.
} 
Desde la historia colonial Trilce Laske, trató el tema en su artículo. "La instrumentalización pública del patriotismo", en donde expuso una polémica intelectual ocurrida en México, a inicios del siglo XVIII, provocada por los discursos de superioridad académica del nuevo arcediano vasco. El artículo cuestionaba la dimensión efectiva del criollismo en Nueva España. En el caso de la polémica, el autor trató de demostrar como el patriotismo surgió como herramienta instrumental en manos de una elite para movilizar el espacio público. ${ }^{12}$ Una vez revisada la bibliografía existente sobre el tema, la pertinencia del presente trabajo de investigación encontró su sustento, en el abordaje teórico-metodológico del análisis del objeto de estudio, las fuentes primarias empleadas y el espacio temporal de observación del concepto de patriotismo. No sólo en una perspectiva de arraigo de un sujeto con la tierra de nacimiento, sino como una acción/reacción de los vecinos/vasallos para solucionar un problema político-jurídico, en ese laboratorio constitucional de la metrópoli española entre 1808-1812. En poco tiempo el sentir de fidelidad fue una apariencia, al transitar de los designios del rey a las obligaciones ciudadanas a los mandatos de la ley.

\section{LOS PRINCIPIOS EN LA EXPLICACIÓN DEL FENÓMENO AL DESARROLLARSE EL PROYECTO}

En el presente artículo, se empleó un método combinado de análisis entre la propuesta de Javier Fernández Sebastián, esto permitió observar el concepto de patriotismo y como denotaba diversas posibilidades de sentido no desde sí mismo, sino desde el acontecer para construir argumentos de legitimación/deslegitimación en la vieja España, entre 1808-1812, por actores con posicionamientos ideológicos diversos. ${ }^{13}$ Relacionado esto, con las ideopraxias de Lucien Jaume, para saber si lo dicho por los actores políticos era lo que hacían; el cómo instrumentaban el concepto de acuerdo con sus propios fines. ${ }^{14}$ Interpretación efectuada partir del derecho natural racionalista de J. Gottlieb Heineccio, esto permitió indagar lo jurídico, en la coyuntura de 1808, desde los propios saberes y el uso dado por los actores políticos en el espacio temporal planteado. ${ }^{15}$ Bajo las categorías de análisis: necesidad, responsabilidad, acción, reacción y fidelidad. El presente artículo tiene como objetivo indagar el concepto de patriotismo, sus diversas posibilidades de sentido no desde sí mismo, sino como era empleado por los súbditos españoles, diferenciados, entre ciudadanos/vecinos de Madrid (autoridades constituidas) y juntistas.

\footnotetext{
12 LASKE, Trilce (2017). "La instrumentalización pública del patriotismo: una controversia intelectual en México", Revista Secuencia, 99, obtenido de la información: http://secuencia.mora.edu.mx/index.php/Secuencia/rt/printerFriendly/1464/1693, el día 20 de septiembre de 2017.

${ }^{13}$ FERNÁNDEZ SEBASTÍAN, Javier, ALJOVÍN DE LOSADA, Cristobal. \& FERES JUNIOR, Joao (2009). Diccionario político y social del mundo iberoamericano. La era de las revoluciones, 1750-1850. Madrid: Centro de Estudios ConstitucionalesFundación Carolina-Sociedad Estatal de Conmemoraciones Culturales.

${ }^{14}$ JAUME, Lucien, (2004), "El pensamiento en Acción: por otra historia de las ideas políticas", Revista Ayer no. 53, pp. 114-115.

15 CASAGRANDE, Agustín. (2016). la historia conceptual y la hermenéutica de la historia del derecho. Revista electrónica del Instituto de Investigaciones Jurídicas y Sociales Ambrosio L. Gioja, 13-14
} 
Fue esta distinción, en el uso del concepto y, como se relacionan con los acontecimientos en el accionar de unos y la reacción de otros en una época de crisis. Esto generó tensión y propició en el vocablo univoco y tradicional de patriotismo su transformación en un concepto sociopolítico al fisurarse uno de sus elementos internos: $L a$ fidelidad jurada. ${ }^{16}$ Metamorfosis afín con los cambios político-jurídicos experimentados en la metrópoli española, esto dividió a la sociedad de la metrópoli española en dos repúblicas, con ideologías y adherencia social a monarcas distintos.

\section{CONCEPTUALIZACIONES E INTERPRETACIONES NECESARIAS EN LA INVESTIGACIÓN}

Para Thomas Hobbes, los hombres en estado de naturaleza tenían la capacidad de alcanzar sus propios fines. El inconveniente se presentaba cuando dos hombres querían un mismo bien; se volvían enemigos y se esforzaban por destruirse, encontrándose en una condición de guerra; era necesario abandonarán el estado en que se encontraban y se sometieran a un orden artificial capaz de crear normas sociales para regir la convivencia armónica entre los hombres. ${ }^{17}$ Sobre el tema John Locke, en el "Segundo Ensayo sobre el Gobierno Civil", establecía: El hombre era una criatura de Dios, no debía destruir su vida ni la de los demás. Por lo tanto, era necesario la existencia de una autoridad, la cual pudiera resolver los conflictos del ser humano con sus semejantes. ${ }^{18}$ Para Rousseau, el contrato social era un vínculo donde los hombres renunciaban al estado de naturaleza para someterse a las reglas sociales, a cambio de un beneficio mayor. ${ }^{19}$

De las teorías expuestas acerca de la naturaleza del gobierno en el pensamiento político clásico, se deducía, el pacto se sujeción, era un acto jurídico-político, con derechos y obligaciones reciprocas entre las partes.

\footnotetext{
${ }^{16}$ El diccionario de la Real Academia de la Lengua Española, en su versión de 1817, conceptualizó, en sentido positivo, al Patriotismo como: "El amor de la patria"; esta definición relacionada con el lugar de nacimiento de un sujeto y el arraigo con la propia tierra trajo consigo un sentido de pertenencia e identificación personal y voluntaria hacia un grupo determinado. Cada asociación trata de infundir esta clase de fervor a través de ciertas prácticas conmemorativas: llámense, fiestas nacionales, hazañas de héroes nacionales, monumentos esculturas, estatuas, por sólo referir algunos ejemplos. En el diccionario ingles Oxford de 1933, la definición actual de patriotismo estableció el carácter o pasión de un patriota; el amor o fervor apasionado por el propio país. En concordancia el diccionario internacional de Webster de 1967, al respecto refería, patriotismo, el amor o pasión por el país; las virtudes y acciones de un patriota. ${ }^{16}$ BAR-TAL, Daniel, (1994). "Patriotismo como creencia fundamental de la pertenencia al grupo", Revista Psicología Política, no. 8, 65. Sin embargo, el Patriotismo también podía conceptualizarse en sentido opuesto, es decir en sentido negativo, cómo una virtud de cumplir los objetivos, ideologías y condiciones de quien ejercía la dominación política, a través de un vínculo como lo era el vasallaje. No fue algo novedoso, desde el último tercio del siglo XVIII, en la ilustración tardía española, en los escritos de Jovellanos, Campomanes o en las disertaciones de las sociedades económicas, se hacía ya la distinción entre "el amor a la patria" como sentimiento a la tierra natal y "patriotismo o virtud cívica" como constante disposición de trabajar por el bien del Estado. PICORNELL, Juan, traducción del libro de Mathon de la Cour, (1790). "Discurso sobre los mejores medios de excitar y fomentar el patriotismo en una monarquía”, Madrid, Aznar, 5-6.

${ }^{17}$ HOBBES, Thomas, (2011). "Leviatán. O la materia, forma y poder de una república eclesiástica y civil". México, Fondo de Cultura Económica, 107.

${ }^{18}$ LOCKE, John, (1991) Segundo ensayo sobre el gobierno civil, traducción castellana, Madrid, Espasa-Calpe, 266.

${ }^{19}$ ROUSSEAU, Jean Jacob, (1991). “El contrato Social”, Madrid, Espasa-Calpe, 35.
} 
Los sujetos contractuales tenían que realizar determinadas acciones en beneficio del otro. El soberano adquiría el compromiso de garantizar la seguridad social frente a las amenazas internas y externas, promulgar leyes suaves y justas, procurar el bien común para lograr la felicidad de los súbditos. Por el otro, el vasallo y/o súbdito, contribuía con su libertad y sus bienes; trataba, ante todo, de cumplir los designios del monarca. Dentro de los elementos esenciales para la existencia del acto jurídico, se encontraban, dos sujetos conformando el pacto social, un cúmulo de derechos y obligaciones reciprocas entre las partes, el consentimiento expreso o tácito y la fidelidad jurada. ${ }^{20} \mathrm{De}$ una interpretación sistemática del concepto de pacto social y de sus elementos internos se advertía: El súbdito o vasallo tenía el deber de cumplir los mandatos y las obligaciones impuestas por el monarca o emperador bajo la ideología política dominante. ${ }^{21}$ En el espacio temporal objeto de estudio existía una distinción del súbdito, entre: Los ciudadanos/vecinos de Madrid (autoridades constituidas) y los juntistas.

\section{LA ALIANZA FRANCO-ESPAÑOLA QUE TRASCENDIÓ EN LOS HECHOS DE BAYONA DE 1808}

A finales de 1799, Napoleón Bonaparte, después de derrocar el Directorio, asciende al poder político francés. ${ }^{22}$ Este acontecimiento, fue un punto clave, incidiría de un modo directo, en la forma de gobernar en la monarquía española, por parte de Carlos IV y su favorito Manuel Godoy, y sus relaciones con Francia. ${ }^{23}$ Hacía 1800, Carlos IV ratificaba la alianza con Francia al suscribir el segundo Tratado de San Ildelfonso. En este nuevo pacto las potencias firmantes pretendían acabar con el poderío naval británico. En el articulado de este documento, se obligaba a España a contribuir económicamente en las guerras de Napoleón, y poner a su disposición la armada española para combatir la flota británica. De igual forma, entrar en guerra con Portugal, quien, al no ceder a las pretensiones franco-españolas, se desencadenó la "guerra de las naranjas", obligándole a

\footnotetext{
${ }^{20}$ La finalidad de este tipo de acto es mantener la palabra dada, debiendo cumplir por sí, las obligaciones contraídas de manera primigenia. Sin poder romper de manera unilateral el pacto por alguna de las partes.

${ }^{21}$ Esto constituía una continuidad en el cambio. En la ruptura española de la primavera de 1808, en un plano de legitimación/deslegitimación los actores políticos aspirantes a ejercer la dominación le exigín al pueblo lealtad. En el diccionario de la Real Academia de la Lengua Española, en sus versiones de 1780 y 1817, se conceptualizaba el súbdito como "el individuo sujeto a la disposición de algún superior, con obligación de obedecer sus mandatos y órdenes. Y definía el vasallaje como "La sujeción de dependencia o reconocimiento del súbdito hacía su señor".

${ }^{22}$ El directorio fue la penúltima forma de gobierno adoptada por la Primera República Francesa, durante la Revolución francesa. Se inició el26 de octubre de 1795, y terminó con el golpe de Estado, protagonizado por Napoleón Bonaparte, del 9 de noviembre de 1799, instaurando el Consulado. Tras el período del Terror impuesto por el ala más extremista de los Jacobinos, se produjo un retorno hacia posiciones más moderadas. GUENIFFEY, Patrice, “Doit-on réhabilitier Robespierre?”, L' historie, julioseptiembre, 2013, Les Collections de Historie, 60, consultada en http://www.lhistoire.fr/doit-r\%C3\%A9habiliter-robespierre el día 18 de enero de 2018.

${ }^{23}$ Manuel Chust al respecto diría respecto a la relación franco-española, "En 1800, [se dio por] conveniencia, en 1805, por necesidad y en 1807, por desesperación”, CHUST, Manuel, (2007), Un bienio Trascendental: 1808-1810 en M. CHUST (coord.), "1808 la eclosión juntera en el mundo hispánico", México, Fondo de Cultura Económica/Fideicomiso Historia de las Américas/Colegio de México, 20-21.
} 
ceder por la fuerza mediante el Tratado de Badajoz, suscrito el 6 de junio de 1801 y el Tratado de Madrid, de 29 de septiembre del mismo año. ${ }^{24}$ En esencia en dichos documentos se acordó que, Portugal cerrará todos los puertos a los buques ingleses y frenar el suministró de auxilio a los países enemigos de Francia. Sin embargo, los planes de Bonaparte no pudieron concretarse a cabalidad. A mediados de 1805 intentó llevar a cabo un plan de distracción al invadir las islas británicas, tratando de alejar a la flota inglesa del canal de la Mancha para dirigirlas a sus posesiones en las Indias Occidentales. El plan fue un fracaso, no pudo llegar a completarse. El 20 de octubre del último año en cita, tuvo acontecimiento la batalla de Trafalgar entre la tercera coalición conformada por Reino Unido, Austria, Rusia, Nápoles y Suecia frente a Francia y España para intentar derrocar del trono imperial a Bonaparte. En estos hechos de guerra, España y Francia perdieron la batalla, como resultado, la armada española fuertemente dañada, fue el fin del monopolio comercial española y el control de sus colonias en América. De tal suerte, se puso fin al plan de derrocar el dominio inglés en el Atlántico.

Al conocer Napoleón la derrota sufrida en Trafalgar y no poder invadir las islas británicas ni poder bloquear su comercio marítimo, planeó una nueva táctica, obstruir a los ingleses en el continente europeo. Para lograr su fin demandaba, nuevamente, el apoyo de España. El 27 de octubre de 1807, fue firmado el Tratado de Fontainebleau cuyo objetivo era la invasión de Portugal y su fragmentación territorial para cortar los suministros a la armada británica. Este nuevo pacto contenía una serie de preceptos legales en los cuales se vislumbraba una nueva trama por parte del emperador de los franceses, obtener la corona de la monarquía española. No le fue difícil conseguir sus propósitos, las diferencias internas entre los borbones le permitieron imponer en corto tiempo a su hermano José Bonaparte, como rey de España e Indias.

El concepto de patriotismo al verse relacionado con el concepto de crisis, el estado de necesidad y el sentido de responsabilidad de los súbditos españoles de la metrópoli de 1808, denotaba una nueva experiencia e indicaba la ruptura de una época, lo cierto fue como afirmará Reinhart Koselleck: "la estabilidad fue vulnerada”. 25 Los actores políticos divergentes del momento, se encontraron en dos posicionamientos ideológicos y afiliaciones políticas específicas, con un fin superior: Mantener la integridad de la monarquía española, pero con objetivos de movilización distintos. Revisaban con detenimiento los elementos esenciales y de validez del pacto social, sus causas de incumplimiento y las prohibiciones legales para modificar el contrato de forma unilateral, no como un proceso coherente y unificado de solución. Al indagar lo jurídico, a partir de sus propios saberes, buscaron una solución a la crisis. En sus discursos decían que, aspiraban a mantener y reformar la monarquía, pero realmente novaban el contrato social de acuerdo con sus propios fines. Esto, realmente, constituyó una verdadera ilusión de

\footnotetext{
${ }^{24}$ CARLOS IV, mediante el "Real Decreto", de 27 de febrero de 1801, declaró la guerra a Portugal, documento consultado en GODOY Manuel, "Memorias de Don Manuel Godoy Príncipe de la Paz o sea cuenta dada de su vida política; para servir a la historia del reinado del señor Carlos IV de Borbón”, Tomo tercero, París, Librería Americana de Lecointe y Laserre, 1839, 312 -314
} 
lealtad al legítimo monarca (Fernando VII) y permitió a los grupos ostentantes del poder político desafiar el orden constituido. Los involucrados, independientemente de su posicionamiento ideológico se plantearon la responsabilidad de actuar. Las tensiones y expectativas por salir de una situación no deseada oscilaron entre, la sumisión y tolerancia al nuevo gobierno o la lucha armada para mantener los dominios a nombre del legítimo monarca. Sin embargo, las formas de persuasión en esa acción/reacción patriótica de los bandos antagonistas en búsqueda de adhesión fueron muy similares, para lograr la confianza de la sociedad española trataron de exaltar la credibilidad de sus acciones. Les exigían como muestras de fidelidad: Donativos, rogativas, contribuciones, incorporación a la milicia para completar sus tropas, regimientos o compañías y el juramento de lealtad y adhesión al grupo. Con ello, el concepto de patriotismo hizo referencia a nuevas cosas, respondió al juego de oposiciones entre los grupos beligerantes, afines a las acciones de: donantes, mozos o afiliados, contribuyentes, benefactores, etcétera.

Al persuadir a la sociedad, los grupos antagonistas trataron de sacar todas las ventajas posibles por conveniencia política, lo que puso al pueblo a elegir y decidir por el partido más conveniente, según sus muy particulares intereses. En consecuencia, frente a las acciones de los franceses y sus satélites se encontraban las reacciones de los juntistas. Así, José I al entrar en España, mediante proclama declaraba sus sentimientos al pueblo conquistado, buscando la ayuda de la nación para recobrar el antiguo esplendor del imperio español, persuadiéndoles de otorgarle juramento de fidelidad. En Tolosa de Guipúzcoa, el 10 de julio de 1808, ordenó se levantarán una serie de distintivos en todas las ciudades, villas y lugares de la metrópoli española anunciando su proclamación. ${ }^{26}$ Otros ejemplos de persuasión para lograr su cometido era, la exigencia de ciertas acciones patrióticas condicionando a la propia sociedad española así el rey José I de España al encontrarse en Vitoria el $1^{\circ}$ de octubre de 1808, ordenaba:

Los empleados, en [cualquier] ramo [ ... y todos los que gocen sueldo [o] pensión de nuestro tesoro público, $[\ldots]$ deben prestarnos el juramento de fidelidad [de no hacerlo], cesarán de percibir este sueldo o pensión ínterin no exista en la Secretaría del [ministro,] a quien corresponda el acto de este juramento. ${ }^{27}$

Al encontrarse en Madrid, el 16 de febrero de 1809, mandaba a los generales y oficiales prestar juramento

\footnotetext{
25 SVAMPA, María Lucila, (2017). El concepto de crisis en Reinhart Koselleck, Polisemias de una categoría histórica". Anacronismo e irrupción. Revista de Teoría y Filosofía Política Clásica y Moderna, 131.

${ }^{26}$ NAPOLEÓN, José I, (1810), "Decreto para la proclamación del rey en todas las ciudades y villas del [reino] en que es costumbre”, dado en Tolosa de Guipúzcoa, el 10 de julio de 1808, en Prontuario de las leyes y decretos del rey nuestro señor José Napoleón I desde el año de 1808, Tomo I, Madrid en la Imprenta Real, 43.

${ }^{27}$ NAPOLEÓN, José I, (1810), “Decreto para que todos los empleados y todos los que tengan sueldo o pensión del tesoro público cesen de percibirlo hasta que conste haber hecho el juramento de fidelidad", dado en vitoria el $1^{\circ}$ de octubre de 1808, en Prontuario de las leyes y decretos del rey nuestro señor José Napoleón I desde el año de 1808, Tomo I, Madrid en la Imprenta Real, 55.
} 
bajo pena de destitución. ${ }^{28}$ Además, fijaba la fórmula que debían prestar los empleados públicos y los individuos nombrados para empleos eclesiásticos. ${ }^{29}$ Del mismo modo, la sociedad española demostraba lealtad al nuevo soberano incorporándose a su ejército o enviando a sus hijos para completar sus tropas. Y si estos últimos participaban en el ejército rival tenía el padre la obligación de incorporar un hombre apto a la causa francesa o aportar una suma de dinero. De ser acaudalados pagarían 12, 000 ducados por cada hombre a presentar. ${ }^{30}$ Igualmente creaba milicias urbanas para la protección de los pueblos y villas. ${ }^{31}$

Durante el verano de 1808, el bando juntista, una vez lograda la victoria de Bailen, se dio cuenta de la imposibilidad de sobrevivir con un gobierno dividido era necesario concentrar el poder en un órgano central. De tal manera, surgió a la luz la Junta Central Gubernativa. En su acta de instalación llevada a cabo en Aranjuez el 25 de septiembre de 1808, intimaba de sus diputados el juramento a la religión católica y fidelidad a Fernando VII, sus derechos y soberanía. ${ }^{32} \mathrm{Al}$ día siguiente de su creación ordenaba a los diversos consejos (de Estado, Indias, Guerra Inquisición, Marina, Órdenes y Hacienda), prestar su juramento al rey legítimo. Le demandaba hicieran extensivo este mandato a justicias, magistrados, virreyes y gobernadores, requiriéndoles obediencia y fidelidad a la Junta Central representante del rey cautivo hasta su regreso. ${ }^{33}$ Igualmente exigía el alistamiento de varones entre 16 y 45 años para completar los regimientos que defendieran las fronteras de la Metrópoli Española. ${ }^{34}$

5. El ser y dejar de ser de los afrancesados, resignificación conceptual del patriotismo

Para Cristóbal Aljovín de Losada, en el periodo comprendido entre 1750-1850, en la monarquía española ciudadano/vecino era un personaje participe de forma activa en la política con deberes y derechos dentro de la comunidad" ${ }^{35}$ Tamar Herzog por su parte establecía al ciudadano/vecino vinculado a lo local, al

\footnotetext{
${ }^{28}$ NAPOLEÓN, José I, (1810), “Decreto en que se ordena que los generales y oficiales presten juramento y, pidan servicio bajo pena de destitución," dado en Madrid el 16 de febrero de 1809, en Prontuario de las leyes y decretos del rey nuestro señor José Napoleón I desde el año de 1808, Tomo I, Madrid en la Imprenta Real, 106-107.

${ }^{29}$ NAPOLEÓN, José I, (1810), "Decreto en el que se fija la fórmula que deben prestar los empleados públicos, dado en Madrid, a 02 de mayo de 1809”, en Prontuario de las leyes y decretos del rey nuestro señor José Napoleón I desde el año de 1808, Tomo I, Madrid en la Imprenta Real, 178.

${ }^{30}$ NAPOLEÓN, José I, (1810), "Decreto por el que se manda que todos los que tengan hijos sirviendo en el ejército de los insurgentes presenten a su costa un hombre apto para las armas, o entreguen una suma en la Tesorería General”, dado en Madrid, el 19 de julio de 1809, en Prontuario de las leyes y decretos del rey nuestro señor José Napoleón I desde el año de 1808, Tomo I, Madrid en la Imprenta Real, 256-257.

${ }^{31}$ NAPOLEÓN, José I, (1810), "Decreto por el que se crean milicias urbanas en el [reino] para que cuiden de la tranquilidad pública”, dado en Madrid, el 20 de julio de 1809, en Prontuario de las leyes y decretos del rey nuestro señor José Napoleón I desde el año de 1808, Tomo I, Madrid en la Imprenta Real, 279-280.

32 JUNTA CENTRAL GUBERNATIVA DEL REINO (1808), "Acta de Instalación de la Junta Central y Gubernativa del Reino", Gaceta de Madrid de 29 de septiembre de 1808, 1217-1218.

33 JUNTA CENTRAL GUBERNATIVA DEL REINO (1808), “Comunicado”, Suplemento a la Gaceta de Madrid de 04 de octubre de 1808, 1250-1252.

${ }^{34}$ JUNTA CENTRAL GUBERNATIVA DEL REINO (1808), "Advertencia”, Gaceta Ministerial de Sevilla del $1^{\circ}$ de junio de $1808,3$.

${ }^{35}$ ALJOVÍN DE LOSADA, Cristóbal, (2009). "Ciudadano y vecino en Iberoamérica, 1750-1850: Monarquía o república”, en FERNÁNDEZ SEBASTÍAN, Javier, ALJOVÍN DE LOSADA, Cristobal \& FERES JUNIOR, Joao. Diccionario político y social
} 
pueblo, a la ciudad y para adquirir dicha distinción, debía ser residente del lugar, tener un terreno, padre de familia, con posición económica elevada y profesar la fe católica. ${ }^{36}$ El diccionario de la Lengua Castellana de 1726 indicaba, vecinos eran quienes dentro de una población determinada gozaban de privilegios, y estaban obligados a sus cargas, sin exenciones. En el Diccionario Castellano (publicado en 1786-1788), se le define como el habitante de una población determinada. ${ }^{37}$ Por su parte, el diccionario de Sebastián Covarrubias de 1611, para la voz ciudadano mencionaba:

"[quien] vive en la Ciudad y come de su Hacienda, renta o heredad: es un estado medio entre caballeros e hidalgos y entre los oficiales mecánicos. Cuéntese entre los ciudadanos los letrados, [quienes] profesan letras, y artes liberales, guardando en esto, para [debido a] repartir los oficios la costumbre y fuero del reino o tierra". ${ }^{38}$

En la monarquía católica, en el espacio temporal en estudio, el ciudadano/vecino era una distinción, se trataba de una persona residente principalmente en la ciudad de Madrid, quien gozaba de ciertos privilegios, formaba parte de la administración pública, los tribunales o pertenecía a una corporación, ya fuerza en la Junta Suprema de Gobierno, el Consejo de Castilla, en una Capitanía General o Audiencia, por soló enunciar algunos ejemplos. Era de condición católica y participó de forma activa en el gobierno de José I de España. ${ }^{39}$

El nivel de compromiso de este grupo con la sociedad española fue muy distinto a la de sus adversarios, los llamados juntistas. Para el primer grupo, el sentido conceptual de patriotismo hizo referencia a otras cosas, relacionadas con un nuevo gobierno, regido por instituciones y leyes impuestas. Las autoridades constituidas, pertenecientes a los más altos cargos de la monarquía española (ciudadanos/vecinos de Madrid), mostraban un rango de superioridad respecto al resto del conglomerado de la sociedad de la Metrópoli española, se veían como un grupo virtuoso y superior al pueblo llano. Quienes consideraron que el reinado de los borbones en España no garantizaba la satisfacción de las necesidades demandadas en tiempos convulsivos. Ante todo, querían mantener el orden público para evitar la ruina de la monarquía y el derramamiento innecesario de sangre. La sumisión, a los franceses fue una causa de utilidad pública basada en dos principios: Tolerancia, para mantener el orden y obediencia, como necesidad ante la coacción de la fuerza de los intrusos. El obedecer al gobierno de José I,

del mundo iberoamericano, Tomo I, Madrid, Fundación Carolina/Sociedad Cultural de Conmemoraciones Culturales/Centro de Estudios Políticos y Constitucionales, 179.

${ }^{36}$ HERZOG, Tamar, (2003), "Defining Nations, Immigrants and Citizens in Early Modern in Spain, and Spanish America", New Haven-Londres, Yale University Press, 6-24

${ }^{37}$ ALJOVÍN DE LOSADA, Cristóbal, (2009). “Ciudadano y vecino en Iberoamérica, 1750-1850: Monarquía o república”, en FERNÁNDEZ SEBASTÍAN, Javier, ALJOVÍN DE LOSADA, Cristobal \& FERES JUNIOR, Joao. Diccionario político y social del mundo iberoamericano, Tomo I, Madrid, Fundación Carolina/Sociedad Cultural de Conmemoraciones Culturales/Centro de Estudios Políticos y Constitucionales, 181-182.

${ }^{38}$ ALJOVÍN DE LOSADA, Cristóbal, (2009). "Ciudadano y vecino en Iberoamérica, 1750-1850: Monarquía o república”, en FERNÁNDEZ SEBASTÍAN, Javier, ALJOVÍN DE LOSADA, Cristobal \& FERES JUNIOR, Joao, Diccionario político y social del mundo iberoamericano, Tomo I, Madrid, Fundación Carolina/Sociedad Cultural de Conmemoraciones Culturales/Centro de Estudios Políticos y Constitucionales, 182.

${ }^{39}$ Este grupo primero se le denominó traidor o satélite, una vez jurada la constitución de Bayona se le conocía como juramentado y finalmente, al retorno de Fernando VII a España, se les denominó afrancesados. 
representó una oportunidad. La prioridad era su propia conservación, evitar el derramamiento de sangre y, su interés: El mantener sus puestos en la administración de gobierno, sus bienes y sacar las mayores ventajas posibles de su situación presente, no importaba quien los gobernará. Su actuación fue pragmática, no les costó trabajo adherirse a las instituciones francesas, ni mucho menos jurar lealtad a Napoleón ni a sus leyes ni instituciones.

La casa reinante de los borbones enajenó el cetro en favor de Napoleón. Los ciudadanos/ vecinos lo que realmente hicieron fue, realizar una interpretación jurídico-política del pacto social, de sus elementos esenciales y de validez; en su entendimiento sabían la nulidad de enajenar la corona de forma unilateral, el pacto no podía ser modificado sin el consentimiento del otro sujeto de la obligación contractual: el súbdito. Entonces asimilaron, ningún español enajenó el cetro ni permitió la conquista de la metrópoli española, sino fueron los propios gobernantes quienes lo hicieron y permitieron a las fuerzas francesas invadir la península. ${ }^{40}$ Desde el momento en que el gobierno legítimo se había separado de su pueblo y no mantenía comunicación alguna con la sociedad se suspendían las obligaciones del pacto, cesaban las acciones del gobierno y, por ende, la obediencia y sumisión de los vasallos. En este nuevo espacio de experiencia, los ciudadanos/vecinos de Madrid (autoridades constituidas aliadas de Bonaparte), no se resistieron a la dominación enemiga, ni tomaron las armas para expulsar a los intrusos y restablecer a sus legítimos gobernantes en el poder. No creían en la vuelta a España de la casa real de los borbones. Desde su mirada "la anarquía era un mal, el gobierno un beneficio público". ${ }^{41}$

Para los aliados de Bonaparte, los sucesos acaecidos en España fueron la oportunidad anhelada de reformar las instituciones de una monarquía perdida, "dirigida por hombres separados de su pueblo entregados a sus pasatiempos y abandonados al mando de hombres sin escrúpulos". ${ }^{42}$ Participaron de manera muy activa en la asamblea convocada en Bayona. En el horizonte de expectativa se les presentaba un nuevo pacto de sujeción que unía a franceses y españoles, no dudaron en jurar fidelidad al nuevo rey, la constitución y sus leyes. ${ }^{43}$ En tal sentido, el concepto de patriotismo, al ser sujeto de debate y relacionarse con un sentido de fractura resignificó su significado, al verse alterado por una serie de intereses sirvió para crear una diferencia del cuerpo político existente e implicó la reconstrucción de la identidad. El ser y dejar de ser fiel a la monarquía tradicional española. En las fuentes analizadas se dejó entrever este nuevo sentido del concepto en estudio, para dar un ejemplo de ello, se utilizó como fuente primaria de análisis, el discurso de Félix José Reinoso en su obra: "Examen de los delitos de infidelidad a la patria: imputados a los españoles sometidos bajo la dominación francesa", al respecto manifestaba:

\footnotetext{
${ }^{40}$ REINOSO, Félix José, "Examen de los delitos de infidelidad a la patria: imputados a los españoles sometidos bajo la dominación francesa,"Auch, Viuda de Duprat, 1816, 3.

${ }^{41}$ REINOSO, Félix José, "Examen de los delitos de infidelidad a la patria: imputados a los españoles sometidos bajo la dominación francesa", Auch, Viuda de Duprat, 1816, 74 .

${ }^{42}$ AZANZA, Miguel José, "Discurso pronunciado por D. José Miguel de Azanza en la apertura de la asamblea de los notables españoles reunidos en Bayona", Bayona, 15 de junio de 1808.

${ }^{43}$ Tal como quedó establecido en el artículo 6 , del Estatuto de Bayona, otorgado el 06 de julio de 1808.
} 
"la patria son los ciudadanos mismos; la patria no quiere la muerte, sino la conservación de los ciudadanos" ${ }^{4}$

Para el grupo afrancesado, el reconocer al rey intruso, recibir su ley, era un acto de heroísmo a la patria, debía anteponerse, sobre todas las cosas, la seguridad como una necesidad. Conservar la monarquía era un fin superior, en nada beneficiaría el enfrentamiento, una prioridad era el evitar el derramamiento de sangre de la sociedad española. Pero, no todos los súbditos reaccionaron de la misma manera a los ciudadanos/vecinos de Madrid. El pueblo llano y algunos miembros de la nobleza (después llamados juntistas), de manera espontánea, reaccionaron violentamente a la ocupación. Se sintieron traicionados por las autoridades constituidas y el antiguo aliado, Napoleón. consideraban que, Fernando VII debía ser restituido en su trono.

6. La reacción juntista. ${ }^{45}$ "Un ojo al gato y otro al garabato" ${ }^{\text {"66. }}$

En la primavera de 1808, cuando el corso francés realmente mostró sus intenciones sobre España no esperaba el levantamiento armado del pueblo llano, al saber que Joaquín Murat, trasladaría a Bayona a la reina de Etruria María Luisa y el infante Francisco de Paula, en donde se encontraban ya reunidos Carlos IV y Fernando VII. Al grito de traición la multitud se congregó en el palacio real y comenzó la insurrección en la Metrópoli española, el 2 de mayo de 1808. La revuelta se extendió por toda la península ibérica. La multitud armada salió a la calle, esto originó una tragedia al enfrentarse al ejército francés, el cual se impuso por la superioridad de las armas. Su paciencia había llegado al límite.

Los leales o juntistas, en los diversos impresos de la época, mostraron una exacerbada exaltación patriótica de fidelidad al rey legítimo Fernando VII, la defensa de la religión católica, las costumbres y la patria. ${ }^{47}$ Manipularon el sentido de pertenencia o cohesión a través de la religión católica, como una carga en el cumplimiento del deber de obediencia a Fernando VII, para influir en la sociedad española a actuar en un sentido determinado. Ejemplo de ello, lo encontramos en la "Proclama de la Populosísima Ciudad de Sevilla dirigida a los españoles", reimpresa en la “Gazeta Extraordinaria de México”, el 1 de agosto de 1808, en donde afirmaba:

"Sevilla no ha podido resistir los impulsos de su heroica lealtad, de que ha dado [ejemplo] en todos los siglos. Se le ha arrebatado el rey $[\ldots]$ Se han pisado las leyes fundamentales de la monarquía, se amenazan los bienes, los usos, las mujeres y [cuanto] tiene precioso la Nación.

\footnotetext{
${ }^{44}$ REINOSO, Félix José, "Examen de los delitos de infidelidad a la patria: imputados a los españoles sometidos bajo la dominación francesa”, Auch, Viuda de Duprat, 1816, 62.

${ }^{45} \mathrm{~A}$ los personajes de los grupos sub alternos de la sociedad española y algunos nobles de la metrópoli, quienes se organizaron por medio de juntas para buscar una salida a la crisis política, de ahí su nombre. Estas instituciones de nuevo cuño, depositarias de la soberanía popular, se formaron al margen del poder constituido, rompiendo con las autoridades establecidas, quienes se habían adherido con los invasores franceses. La justificación del surgimiento del movimiento juntista para reaccionar frente a los invasores fue, el abandono por parte de gobierno, quien les ordenaba callar y obedecer, el cautiverio del legítimo rey a manos del antiguo aliado. La Junta de Asturias decía: "Sin gobierno y en orfandad, por el rapto de [... Fernando VII, [... ] llevado a la fuerza por su opresor y $[\ldots]$ amenazados los más caros intereses de los españoles, la religión, la patria y el rey”. ÁLVAREZ VALDÉS, Ramón (1889), "Memorias del levantamiento de Asturias en 1808", Oviedo, Imprenta del hospicio provincial, 20.

46 "Un ojo al gato y otro al garabato", es un dicho popular mexicano, significa estar atento a varias cosas al mismo tiempo, en el contexto de este artículo su significado hace referencia a la atención del bando juntista a las acciones de los franceses y sus satélites.

${ }^{47}$ GUERRA, François Xavier, Modernidad e independencias, México, Fondo de Cultura Económica, 2014. 149.
} 
La religión Santa, única esperanza nuestra, va a perecer $[\ldots]$ todo por $[\ldots]$ engaño, $[$ de quienes] se llaman cabezas de nuestro gobierno. ${ }^{48}$

Este grupo como reacción consideraban que hacían en el uso y manipulación del lenguaje, a través de la palabra escrita y su circulación, era el tomar las armas y sacrificar sus vidas para poder expulsar al invasor y sus satélites, resguardar los bienes de la corona hasta el retorno de su monarca legítimo. Quienes consideraron la no intervención de una dominación política extranjera en sus decisiones políticas internas ni en el otorgamiento de legislación diversa a la que durante muchos siglos había dominado la escena jurídica-política española y la relación entre el rey y sus vasallos. Pero, se vieron en la imperiosa necesidad de justificar su reacción frente a sus adversarios, le trataron dar solución a la nula abdicación de la corona española en manos de Napoleón, empleando sus propios saberes jurídicos. La intensidad en la reacción de rechazo al antiguo aliado, al hoy invasor, remitió a este grupo, a algo más moderno. En el dialogo, principalmente en la voz de Manuel José Quintana, se dejaba entrever el cambio, no como una regeneración, sino como una invención, solo tuvieron que esperar la oportunidad para mostrarse de forma abierta. No como lo habían hecho las autoridades constituidas ciudadanos/vecinos de Madrid. En el "Manifiesto de la Junta Central Gubernativa del Reino", de 26 de octubre de 1808, redactado por este autor, mencionaba:

"Sí españoles, alumbrará el gran día [..., conforme a los deseos de nuestro amado soberano y su leal pueblo, la monarquía se establezca sobre sólidas y verdaderas bases. Contareís entonces, con leyes fundamentales y benéficas [para proteger] el orden y [eliminar] el poder arbitrario $[\ldots]$ La revolución española tendrá de este modo un carácter totalmente diferente de la Revolución Francesa" ${ }^{49}$

Mientras decían expresar sus sentimientos y aflicciones patrióticas con el rey legítimo, la religión y la patria, lo que realmente hacían, era seguir muy de cerca los ideales, leyes e instituciones impuestas en España por Napoleón. Ya "echaban un ojo al gato y otro al garabato", sabían el origen de todos sus males y como podían solucionarlos. La influencia francesa en las prácticas políticas juntistas se encontraban, por citar algún ejemplo: Si los americanos habían rechazado la propuesta de José I de enviar representantes para participar en el gobierno afrancesado era necesario la toma de acciones para contener el deseo americano a la representación. ${ }^{50}$ Por lo tanto, el juntismo en sus diversas manifestaciones (las juntas provisionales, la Junta Central, la Primera Regencia o las Cortes de Cádiz), buscaron la fidelidad americana, preocupadas por anular las propuestas napoleónicas. O como en la búsqueda o confirmación de la adhesión social y de las instituciones americanas, los juntistas de iure cedieron permitiendo la representación americana en el centro del gobierno monárquico.

La sociedad tenía el conocimiento suficiente de los acontecimientos políticos, a través de las diferentes

\footnotetext{
48 SUPREMA JUNTA DE GOBIERNO DE SEVILlA (1808), "Proclama de la Populosísima Ciudad de Sevilla dirigida a los españoles”, reimpresa en la Gazeta Extraordinaria de México del $1^{\circ}$ de agosto de 1808, Tomo XV, número 66, Ciudad de México, 515.

49 QUINTANA, Manuel José, “Manifiesto de la Junta Central Gubernativa del Reino”, Aranjuez, 26 de octubre de 1808”, en GUERRA, François Xavier, Modernidad e independencias, México, Fondo de Cultura Económica, 2014, 141.
} 
formas de divulgación, sólo requerían la fuerza política y militar para echar a andar sus proyectos. En este sentido el concepto de patriotismo se resignificó en un sentimiento de lealtad al legítimo monarca, sin embargo, su significado conceptual tenía dos caretas: Una de aflicción, conmoción, dolor, la tristeza y pesadumbre de lo acontecido y otra de invención, por lo propio por lo nacional, en donde, la renovación política debiera ser única y exclusivamente de los españoles, sin injerencia externa. Esto último, en poco tiempo evolucionaría las ideas de la sociedad española y mutaría el sentido conceptual de patriotismo, en una aspiración de cosas a las que se anhelaba volver y no existían, debían ser creadas para darles nuevamente vida. En el "Proyecto de decreto sobre restablecimiento y convocatoria de Cortes o consulta al país", del 13 de mayo de 1809, se argumentaba:

"Sin constitución, toda reforma es precaria, toda prosperidad es incierta; sin ella, los pueblos [eran] rebaños de esclavos, movidos al arbitrio de una voluntad injusta y desenfrenada, siempre; sin ella, las fuerzas de la sociedad entera destinadas a procurar el mayor bien de todos sus miembros se empleaban exclusivamente en contentar el orgullo y saciar el frenesí de unos pocos o de uno solo". ${ }^{51}$

Mediante la interpretación y reinterpretación de las doctrinas neo-escolásticas acerca de la retroversión de la soberanía de la comunidad circulantes y una participación social activa en la vida política. En realidad, se trató de una reacción al gobierno, las leyes y las instituciones de Napoleón impuestas en España. Las ideas de la ilustración francesa y eran conocidas por las elites españolas desde la segunda mitad del siglo XVIII, sólo necesitaron florecer en el momento preciso. Hacía 1810-1811, el empleo de la figura real sólo fue un antifaz destinado a la conquista de una nueva libertad. El afecto y la pasión por lo propio comenzó a emerger. La sociedad se interesó por un gobierno nacional activo. Como lo dijera François Xavier Guerra: “... la vuelta a una edad de oro no podía consistir en una restauración, sino, una invención, obra de la razón ..." ${ }^{52}$ El retorno de una época con un gobierno representativo para solucionar los males que padecía la monarquía, en su época presente:

"Un rey aislado de la sociedad $[\ldots]$ delegaba sus funciones en su valido, sin importarle los problemas sociales, económicos, políticos, militares y las angustias [del] imperio, en los dos lados del atlántico, ante las malas decisiones de los funcionarios públicos.". 53

\footnotetext{
${ }^{50}$ CASTEL, Jorge (1950), La Junta Central Suprema y Gubernativa de España e Indias, Madrid, Imprenta Marte, 71-76.

${ }^{51}$ JUNTA SUPREMA CENTRAL GUBERNATIVA DEL REINO, "Proyecto de decreto sobre restablecimiento y convocatoria de Cortes o consulta al país", del 13 de mayo de 1809, Consultada el día 24 de septiembre de 2017, en la red mundial de la información: http://www.cervantesvirtual.com/obra/proyecto-de-decreto-sobre-restablecimiento-y-convocatoria-de-cortes-oconsulta-al-pais-13-de-mayo-de-1809--0/

${ }^{52}$ GUERRA, François Xavier, Modernidad e independencias, México, Porrúa, 2014, 30.

53 “Valido", así era conocido Manuel GODOY ÁLVAREZ DE FARIA RÍOS SÁNCHEZ ZARZORA. Nació en Badajoz España en 1767 y murió en Francia en 1851. Noble y político español favorito de Fernando VII, entre 1792 y 1798, y hombre fuerte en la sombra de 1800 a 1808. Fue duque de la Alcudia y de sueca, príncipe de la Paz por su negociación de la Paz de Basilea en 1795. Como secretario de Estado (1792-1798) y generalísimo (1801-1808) estuvo al frente del Gobierno de España durante la crisis europea provocada por la Revolución francesa y las ambiciones de Napoleón Bonaparte, culminó con la invasión francesa de 1808 y la guerra de Independencia, pocos meses después de la caída de Carlos IV y el propio Godoy a causa del Motín de Aranjuez. A lo largo de su valimiento, lleno de luces y sombras, logró mantener la situación de España ante el poderío de Francia con una política exterior pragmática, mientras en el interior trató de llevar a cabo un programa reformista ilustrado, generó un profundo rechazo en muchos grupos sociales, en especial entre la nobleza y el clero. Citado en LÓPEZ CANCELADA, Juan, "Sucesos de Nueva España hasta la coronación de Iturbide”, estudio introductorio y notas de ZÁRATE CASTRO, Verónica. México, Instituto Mora, 67.
} 
El cómo y el quién debía cumplir el contrato social fue el problema principal de la representación, en la justificación transitó del pensamiento a la expresión de los ideales de la retroversión de la soberanía. En esa reacción, frente a la otredad, trataron de sustituir a uno de los elementos subjetivos del pacto: El rey por su imagen. Con ello trataron de hacer presente al rey legítimo ausente a quien debían fidelidad, administrándole sus bienes hasta su retorno. No obstante, la intencionalidad de este grupo no fue una tarea fácil, tuvieron enormes problemas, existían pueblos con una percepción de superioridad frente a otros. Tal es el caso de Sevilla, donde se erigió una junta que se auto-otorgaba facultades superiores, nombrándose Suprema Junta de Gobierno de España e Indias, sin consultar a otras, buscó el reconocimiento americano y obtener recursos para continuar la guerra. Disposiciones discrepantes y contradictorias minaban sus aspiraciones y eran fácilmente superadas por los ejércitos franceses, necesitaban coordinarse en un organismo regulador de todas. La Junta Central Gubernativa del Reino, creada con esta intención, el 25 de septiembre de 1808, no era suficiente, le faltaba un elemento esencial de todo pacto, el consentimiento de todos los pueblos integrantes de la monarquía española, dando lugar a una legitimación política cuestionable. En búsqueda de aprobación, sufrió un fuerte desgaste, nunca logro consolidar su autoridad, finalmente se desintegró. Uno de los aciertos de este organismo político en transición fue la idea de convocar a Cortes, No pudo llevarla a la práctica por el estado de guerra existente, pero quedó ahí, como una posibilidad real. Planteamiento retomado después por el Primer Consejo de Regencia, quien emitió la convocatoria respectiva en todos los territorios del imperio español.

Una vez establecida la asamblea parlamentaria extraordinaria, en la ciudad de Cádiz en 1810, los juntistas peninsulares, lo que realmente hicieron, fue inventar algo nuevo con elementos ideológicos y prácticos a su alcance, entre transición, tradición y modernidad, sin precedente en las leyes fundamentales de España. Para este grupo, la reacción frente a la otredad y los hechos vergonzosos de Bayona los llevó, desde, mayo-junio de 1808 hasta 1812, a promulgar un nuevo pacto social denominado: Constitución Política de la Monarquía Española. En este cuerpo normativo de forma expresa aparecen novados algunos de los elementos internos del propio concepto de patriotismo, se sustituyó la lealtad a la figura del rey por parte de sus súbditos a las obligaciones ciudadanas impuestas a los mandatos de la ley. ${ }^{54}$ En el capítulo segundo, artículos, 6, 7, 8, y 9 de la Ley Suprema de referencia se estableció:

"Artículo 6. El amor a la patria es una de las principales obligaciones de todos los españoles, y asimismo el ser justos y benéficos. Artículo 7 . Todo español está obligado a ser fiel a la constitución, obedecer las leyes y respetar las autoridades establecidas. ${ }^{55}$ Artículo 8. También está obligado todo español a defender la patria con las armas, cuando sea llamado

\footnotetext{
${ }^{54}$ Prácticas políticas de influencia francesa, sobre todo lo plasmado en el artículo $7^{\circ}$ de la Constitución de Bayona, decía: "Juro fidelidad y obediencia al Rey, a la constitución y a las leyes ..."

${ }^{55}$ Lo resaltado es propio.
} 


\section{por la ley." ${ }^{36}$}

Pero, no fue lo único que hicieron los juntistas peninsulares en esta temporalidad, en ese sentido de identidad por lo propio, por lo nacional, por ser parte de la representación política, cuyos postulados ideológicos y prácticas políticas llegaran a oídos de los americanos. ${ }^{57}$ Este discurso ideológico al ser empleado por diversos actores en contextos espacio temporales diversos, dieron origen a una serie de agravios en contra de los juntistas peninsulares. En un plano de contradicción, no le permitieron al americano reaccionar de la misma forma frente al invasor francés y sus aliados, dando origen a una serie de agravios de represión y desigualdad en contra de los peninsulares por parte de los criollos. Así el concepto de patriotismo en América tuvo ciertas mutaciones en su significado. Al surgir algunos esbozos constitucionales por parte de gobiernos alternos plasmaron los ideales gaditanos. También conforme a sus propios intereses se novaron elementos internos del concepto en estudio, se sustituyó la lealtad a la figura del rey por las obligaciones impuestas en la ley.

Ejemplos de ello, los encontramos en: El artículo 41, del "Decreto Constitucional para la Libertad de la América Mexicana" promulgada en Apatzingán, el 22 de octubre de 1814. "Las obligaciones de los ciudadanos para con la patria son: una entera sumisión a las leyes, un obedecimiento absoluto a las autoridades constituidas, una pronta contribución a los gastos públicos, un sacrificio voluntario de los bienes y de la vida cuando sus necesidades, lo exijan. El ejercicio de estas virtudes forma el verdadero patriotismo" ${ }^{58}$ La Constitución de Cundinamarca, promulgada en Santa Fe de Bogotá, en 1811, en su Título X, del tesoro Nacional, artículo 1ª al respecto refería: "Todo ciudadano tiene obligación de contribuir al culto divino y la subsistencia para los ministros del Santuario; para los gastos del Estado, la defensa y seguridad de la patria, el decoro y la permanencia de su gobierno, la administración de justicia, y la Representación Nacional”. Constitución de Cundinamarca, su capital Santa fe de Bogotá, promulgada en la imprenta patriótica de D. Nicolás Calvo y Quijano, año de 1811, Título X, del Tesoro Nacional, artículo $1^{\circ}$, "Todo ciudadano tiene obligación de contribuir para el culto divino y la subsistencia para los Ministros del Santuario; para los gastos del Estado, la defensa y seguridad de la patria, el decoro y la permanencia de su Gobierno, la administración de justicia y la Representación Nacional”. ${ }^{99}$ Constitución Federal para los Estados de Venezuela. Promulgada el 21 de diciembre de 1811, capítulo octavo, los derechos del hombre se reconocerán y respetarán en toda la extensión del Estado, sección tercera. Artículo

\footnotetext{
${ }^{56}$ CORTES EXTRAORDINARIAS DE CÁDIZ, “Constitución Política de la Monarquía Española”, promulgada en Cádiz el 19 de marzo de 1812, en TENA RAMÍREZ, Felipe, (2005). Leyes fundamentales de México, México, Porrúa, 2005, 60-61.

${ }^{57}$ La parte americana de la monarquía española no es motivo de análisis en el presente trabajo, pero puede llegar a ser un referente para futuras investigaciones sobre el concepto en los bosquejos constitucionales del espacio americano.

${ }^{58}$ CONGRESO DE CHILPANCINGO, "Decreto Constitucional para la Libertad de la América Mexicana” promulgada el 22 de octubre de 1814, en TENA RAMÍREZ, Felipe, Leyes fundamentales de México, México, Porrúa, 2005, 36.

${ }^{59}$ CONSTITUCIÓN DE CUNDINAMARCA, su capital Santa fe de Bogotá, promulgada en la imprenta patriótica de D. Nicolás Calvo y Quijano, año de 1811, Título X, del tesoro Nacional, artículo $1^{\circ}$ Consultada el día 24 de septiembre de 2017, obtenido de la red mundial de la información: http://www.bdigital.unal.edu.co/25/1/constitucion_de_cundinamarca_1811.pdf, el día 30 de octubre de 2017.
} 
194. "Son deberes de cada individuo para con la sociedad vivir sometido a las leyes obedecer y respetar los magistrados y autoridades constituidas, $[\ldots]$ contribuir a los gastos públicos y servir a la Patria cuando ella lo exige, haciéndole el sacrificio de sus bienes y de su vida, si es necesario" ${ }^{60}$

\section{¡TODOS ERAN AFRANCESADOS!}

En conclusión, terminada la guerra de sucesión española, comenzó una época de influjo de las ideas ilustradas en España, siendo unos de sus principales exponentes: Melchor Rafael de Macanaz y Fray Jerónimo Benito Feijoo, quienes hicieron hincapié de desterrar viejos abusos de poder e instaurar nuevas reformas políticas y económicas, en una monarquía decadente, basada en la conquista y no en el comercio. ${ }^{61}$ Desde la asunción de los borbones en España empezaron a implementar primero en la metrópoli y con posterioridad en los territorios de ultramar una serie medidas de carácter económico, político, militar y administrativo para tener un mejor control de ese enorme imperio. Las elites españolas de la época, quienes participaron de forma activa en la administración pública, sobre todo bajo el reinado de Carlos III, trataron de llevar a la práctica política las nuevas ideas de la ilustración. Analizaron la forma de darle solución a los problemas económicos del imperio español, el estudio de la economía cambió su percepción de hacer política. Si bien, los hechos lamentables acaecidos en la Francia revolucionaria, en la última década del siglo XVIII, generaron temor en el monarca español Carlos IV, viéndose en la necesidad de dictar una serie de disposiciones para controlar lo que se leía o no en la monarquía española. No fue suficiente, en los espacios público y privado de sociabilidad, durante el siglo de las luces, se había expuesto la realidad española, debatido con argumentos las necesidades sociales y de regeneración políticajurídica y económica, con ello, aparecieron propuestas de lo que debía cambiar y cómo hacerlo. De ahí, en el problema surgido por la entrega de la corona de España e Indias a Napoleón, en los primeros días de mayo de 1808, "las ideas se transformaron y con ello los signos lingüísticos". ${ }^{62}$ Desencadenando el transito del pensamiento a la expresión del sentir social en la toma de decisiones en el gobierno central de la monarquía. No como algo espontáneo surgido al calor del momento, sino como una semilla sembrada germinada, madurada con deseos de

\footnotetext{
${ }^{60}$ CONSTITUCIÓN FEDERAL PARA LOS ESTADOS DE VENEZUELA. Promulgada el 21 de diciembre de 1811, capítulo octavo, [los [ derechos del hombre [ ... ] se reconocerán y respetarán en toda la extensión del Estado, sección tercera. obtenido de la red mundial de la información: http://www.cervantesvirtual.com/portales/constituciones_hispanoamericanas/obravisor/constitucion-federal-de-los-estados-de-venezuela-21-de-diciembre-1811/html/86de8dbc-4b14-4131-a616-

9a65e65e856a_2.html\#I_30_, el día 30 de octubre de 2017.

${ }^{61}$ DIEZ DEL CORRAL, Luis, La monarquía hispánica en el pensamiento político europeo. De Maquiavelo a Humboldt, en FERNÁNDEZ SEBASTÍAN, Javier, ALJOVÍN DE LOSADA, Cristobal \& FERES JUNIOR, Joao, Diccionario político y social del mundo iberoamericano, Tomo I, Madrid, Fundación Carolina/Sociedad Cultural de Conmemoraciones Culturales/Centro de Estudios Políticos y Constitucionales, 313 .

${ }^{62}$ PALTI, Elías (2011), "Ideas, conceptos, metáforas. La tradición alemana de historia intelectual y el entramado del lenguaje". En FERNÁNDEZ SEBASTIÁN, Javier y CAPELLÁN DE MIGUEL, Gonzalo, Lenguaje, tiempo y modernidad. Ensayos de historia Conceptual, Chile, Globo Editores, 213-241.
} 
florecer. Desde el primer momento, todos eran afectos a un sentir de cambio, de regeneración, de mantener la integridad de la monarquía española, sin embargo, los grupos antagonistas se deslizaron en líneas paralelas en opuesta dirección. El adoctrinamiento francés y las prácticas políticas de los satélites sobrepusieron e impregnaron las ideas de los juntistas. Estos últimos siempre estuvieron atentos de las acciones de sus oponentes para reaccionar, repercutiendo en el constitucionalismo gaditano de 1812 .

La tensión entre la experiencia propia, el adoctrinamiento francés y la esperanza de devolver al imperio español a una época de gloria, provocó soluciones alternativas para en el futuro evitar excesos de la casa gobernante, como había acontecido bajo el reinado de Carlos IV. Esas fuerzas externas, surgidas por la abdicación borbónica de 1808, generaron tensión y fisura en uno de los elementos internos del propio concepto de patriotismo: la fidelidad jurada. Este quebrantamiento se vio reflejado en las acciones/reacciones de los propios actores políticos de la metrópoli española, quienes "entraron en un juego de posibilidades para cumplir una realidad futura”, el consolidar a la sociedad civil como parte activa de la dominación política. ${ }^{63}$ Se dividió a la sociedad española en dos repúblicas con monarcas distintos.

De esta manera, el vocablo en análisis se mostró polisémico, con un sentido de lealtad diverso para distintos hablantes en un mismo espacio temporal, de acuerdo con sus particulares circunstancias y posturas ideológicas, resumía un entramado de experiencias político-jurídicas y necesidades sociales. Ese discurso, de los bandos antagonistas, cargado de ideas en torno a la dominación política, al poner en marcha ciertas prácticas políticas de nuevo cuño colocaron a la ley como autoridad superior, al rey en un segundo plano, como titular del Poder Ejecutivo, quien debía gobernar conforme a la ley. Ahora el concepto de patriotismo adquiría un nuevo significado, sociopolítico-jurídico, en la recomposición de la lealtad jurada del vasallo con su monarca, transformándose en la obligación ciudadana a los mandatos de la ley. Sólo podía exigirse obediencia conforme a la ley.

\title{
PATRIOTISM. A CONCEPT OF ACTION AND REACTION. RESPONSIBILITY TO ACT IN TIMES OF CRISIS (1808-1812)
}

\begin{abstract}
The research used methodologically, comparative conceptual history related to ideopraxist and legal knowledge of political actors in the proposed time space. The objective was to investigate the concept of patriotism, its diverse possibilities of meaning not from itself, but as it was used by the Spanish subjects, differentiated, between citizens / neighbors of Madrid (constituted authorities) and juntistas. From the results obtained it was observed that, between the action / reaction of one and the other, the concept acquired new meanings, in the recomposition of the sworn allegiance of the vassal with his monarch, transforming into citizen obligations to the legal mandates.
\end{abstract}

${ }^{63}$ KOSELLECK, Reinhart (1993), "Futuro Pasado. Para una semántica de los tiempos históricos", Barcelona/buenos Aires/México, Ediciones Paidos, 342. 
Keywords: Necessity; Responsibility; Action; Reaction; Fidelity.

\section{FUENTES DE CONSULTA}

ACEVEDO TARAZONA, Á., \& CARDENAS NARANJO, J. (2017). Resignificar el pasado para ser libres: resemantización ideológica de los conceptos colonia y patria, 1790-1830. Revista Psicoespacios, 11(19), 249-268.

ALJOVÍN DE LOSADA, C. (2009). "Ciudadano y vecino en Iberoamérica, 1750-1850: Monarquía o república", en Diccionario político y social del mundo iberoamericano, Tomo I, Madrid, Fundación Carolina/Sociedad Cultural de Conmemoraciones Culturales/Centro de Estudios Políticos y Constitucionales.

ÁLVAREZ VALDÉS, R. (1889), "Memorias del levantamiento de Asturias en 1808”, Oviedo, Imprenta del hospicio provincial, 20.

BAR-TAL, D. (1994). Patriotismo como creencia fundamental de pertenencia al grupo. Revista de Piscología Política, 63-85.

CASAGRANDE, A. (2016). la historia conceptual y la hermenéutica de la historia del derecho. Revista electrónica del Instituto de Investigaciones Jurídicas y Sociales Ambrosio L. Gioja, 13-14.

CASTEL, J. (1950), La Junta Central Suprema y Gubernativa de España e Indias, Madrid, Imprenta Marte.

COLEGIO ELECTORAL CONSTITUYENTE, (30 de marzo de 1811). Constitución de Cundinamarca,

Universidad Nacional de Colombia. Obtenido de:
http://www.bdigital.unal.edu.co/25/1/constitucion_de_cundinamarca_1811.pdf

CONGRESO DE CHILPANCINGO. (2005). Decreto Constitucional para la Libertad de la América Mexicana. En F. Tena Ramírez, Leyes fundamentales de México, 1808-2005 (pág. 36). México: Porrúa.

CONGRESO CONSTITUYENTE DE 1811. Constitución Federal para los Estados de Venezuela (21 de diciembre de 1811). Obtenido de Biblioteca Virtual Miguel de Cervantes: http://www.cervantesvirtual.com/portales/constituciones_hispanoamericanas/obra-visor/constitucion-federalde-los-estados-de-venezuela-21-de-diciembre-1811/html/86de8dbc-4b14-4131-a616-

9a65e65e856a_2.html\#__30_.

CORTES EXTRAORDINARIAS DE CÁDIZ. (2005). Constitución Política de la Monarquía Española de 1812. En F. Tena Ramírez, Leyes fundamentales de México, 1808-2005 (págs. 60-61). México: Porrúa.

CHUST, M. (2007), Un bienio Trascendental: 1808-1810 en M. Chust (coord.), 1808 la eclosión juntera en el mundo hispánico, (pág. 20-21), México, Fondo de Cultura Económica/Fideicomiso Historia de las Américas/Colegio de México.

DE AZANZA, M. (21 de junio de 1808). El discurso pronunciado por el Sr. D. Miguel José de Azanza en la abertura de la asamblea de los Notables españoles reunidos en Bayona, de la que es presidente. Suplemento a la Gazeta de Madrid, págs. 620-621. 
DIEZ DEL CORRAL, L. (1976), "La monarquía hispánica en el pensamiento político europeo. De Maquiavelo a Humboldt", Revista de occidente, no. 12, Madrid, 2-7.

DI MEGLIO, G. (2008). Patria. En N. Goldman, Lenguaje y revolución. Conceptos políticos clave en el Río de la Plata, 1780-1850 (págs. 115-130). Buenos Aires: Prometeo.

DUSSO, G. (1998),“Historia conceptual como filosofía política”, Res pública, número 1, 35-36, 56.

ENTIN, G. (2013). El patriotismo americano en el siglo XVIII: ambigüedades de un discurso político hispánico. En V. Hébrard, \& G. Verdo, Las independencias hispanoamericanas. Un objeto de Historia (Vol. 137, págs. 1933). Madrid: Casa de Velázquez.

FERNÁNDEZ SEBASTÍAN, J., ALJOVÍN DE LOSADA, C., \& FERES JUNIOR, J. (2009). Diccionario político y social del mundo iberoamericano. La era de las revoluciones, 1750-1850. Madrid: Centro de Estudios Constitucionales-Fundación Carolina-Sociedad Estatal de Conmemoraciones Culturales.

FISKE, S., \& TAYLOR, S. (1984). Social Cognition. New York: Random House.

GADAMER, H. (1998). Verdad y Método. Fundamentos de una Hermenéutica Filosófica. Salamanca: Sígueme. GODOY M. Memorias de Don Manuel Godoy Príncipe de la Paz o sea cuenta dada de su vida política; para servir a la historia del reinado del señor Carlos IV de Borbón, Tomo tercero, París, Librería Americana de Lecointe y Laserre, 1839, 312-314.

GUENIFFEY, P. “Doit-on réhabilitier Robespierre?”, L’ historie, julio-septiembre, 2013, Les Collections de Historie, 60, obtenido de http:/ /www.lhistoire.fr/doit-r\%C3\%A9habiliter-robespierre.

GUERRA, F. (2014). Modernidad e independencias. México: Porrúa.

HABERMAS, J. (2007). Identidades nacionales y postnacionales. Madrid: Tecnos.

HERZOG, T. (2003), "Defining Nations, Immigrants and Citizens in Early Modern in Spain, and Spanish America”, New Haven-Londres, Yale University Press.

HOBBES, T. (2011). Leviatán. México: Fondo de Cultura Económica.

JAUME, L. (2004). El pensamiento en acción: por otra historia de las ideas políticas. Revista Ayer (53), 114-115.

JUNTA SUPREMA CENTRAL GUBERNATIVA DEL REINO. (13 de mayo de 1809). Proyecto de Decreto sobre el restablecimiento y convocatoria de Cortes o consulta del país. Obtenido de Biblioteca Virtual Miguel de Cervantes: http://www.cervantesvirtual.com/obra/proyecto-de-decreto-sobre-restablecimiento-y-convocatoriade-cortes-o-consulta-al-pais-13-de-mayo-de-1809--0/

"Acta de Instalación de la Junta Central y Gubernativa del Reino", Gaceta de Madrid de 29 de septiembre de $1808,1217-1218$.

"Advertencia", Gaceta Ministerial de Sevilla del $1^{\circ}$ de junio de 1808,3.

"Comunicado", Suplemento a la Gaceta de Madrid de 04 de octubre de 1808, 1250-1252.

KARSTEN, P. (1978). Patriots-heroes in England and America: Political symbolism and chamging values over three centuries. Madison: University of Wisconsin Press. 
KOSELLECK, R. (1993), Futuro Pasado. Para una semántica de los tiempos históricos, Barcelona/buenos Aires/México, Ediciones Paidos.

LASKE, T. (2017). La instrumentalización pública del patriotismo. Una controversia intelectual en México. Revista Secuencia (99).

LOCKE, J. (1991). Segundo ensayo sobre el gobierno civil. Madrid: Espasa.

LÓPEZ CANCELADA, J. (2008). Sucesos de Nueva España hasta la coronación de Iturbide. México: Instituto Mora.

MOLINER PRADA, A. (2007), El movimiento juntero en la España de 1808, en M. Chust, (coord..), 1808, la eclosión juntera en el mundo hispano, (pág. 51-52), México, Fondo de Cultura Económica/Fideicomiso Historia de las Américas/El Colegio de México.

MORA CAICEDO, Á. (2013). La transición de vasallos del rey a ciudadanos de la república en Pasto, 1809-1824. Tesis de Magíster en Historia, 23. Médellín, Colombia: Universidad Nacional de Colombia.

NAPOLEÓN,J. (1810), "Decreto en el que se fija la fórmula que deben prestar los empleados públicos”, dado en Madrid, a 02 de mayo de 1809, en Prontuario de las leyes y decretos del rey nuestro señor José Napoleón I desde el año de 1808, Tomo I, Madrid en la Imprenta Real, 178.

"Decreto en que se ordena que los generales y oficiales presten juramento y, pidan servicio bajo pena de destitución", dado en Madrid el 16 de febrero de 1809, en Prontuario de las leyes y decretos del rey nuestro señor José Napoleón I desde el año de 1808, Tomo I, Madrid en la Imprenta Real, 106-107.

"Decreto para la proclamación del rey en todas las ciudades y villas del [reino] en que es costumbre", dado en Tolosa de Guipúzcoa, el 10 de julio de 1808, en Prontuario de las leyes y decretos del rey nuestro señor José Napoleón I desde el año de 1808, Tomo I, Madrid en la Imprenta Real, 43.

"Decreto para que todos los empleados y todos los que tengan sueldo o pensión del tesoro público cesen de percibirlo hasta que conste haber hecho el juramento de fidelidad", dado en vitoria el $1^{\circ}$ de octubre de 1808 , en Prontuario de las leyes y decretos del rey nuestro señor José Napoleón I desde el año de 1808, Tomo I, Madrid en la Imprenta Real, 55.

"Decreto por el que se crean milicias urbanas en el [reino] para que cuiden de la tranquilidad pública", publicado en Madrid, el 20 de julio de 1809, en Prontuario de las leyes y decretos del rey nuestro señor José Napoleón I desde el año de 1808, Tomo I, Madrid en la Imprenta Real, 279-280.

"Decreto por el que se manda que todos los que tengan hijos sirviendo en el ejército de los insurgentes presenten a su costa un hombre apto para las armas, o entreguen una suma en la Tesorería General", publicado en Madrid, el 19 de julio de 1809, en Prontuario de las leyes y decretos del rey nuestro señor José Napoleón I desde el año de 1808, Tomo I, Madrid en la Imprenta Real, 256-257.

PALTI, Elías (2011), "Ideas, conceptos, metáforas. La tradición alemana de historia intelectual y el entramado del lenguaje". En J. Fernández Sebastián y G. Capellán de Miguel, Lenguaje, tiempo y modernidad. Ensayos de historia Conceptual, Chile, Globo Editores, 213-241.

PICORNELL, J. (1790). Discurso sobre los mejores medios de excitar y fomentar el patriotismo en una monarquía. Madrid: Aznar.

POVEA MORENO, I. (2012). Una encrucijada conceptual en el marco de las independencias: La voz patria, Perú 1808-1814. Revista Chronica Nova, 38, 59-80. 
QUINTANA, M. (26 de octubre de 1808). Manifiesto de la Junta Central Gubernativa del Reino. En F. Guerra, Modernidad e Independencias (pág. 141). México: Fondo de Cultura Económica.

REAL ACADEMÍA DE LA LENGUA. (1729). Diccionario de Autoridades de la Real Academía de la Lengua Española. Obtenido de: http://web.frl.es/DA.html.

REINOSO, F. (1816). Examen de los delitos de infidelidad a la patria: imputados a los españoles sometidos a la dominación francesa. Auch: Viuda de Duprat.

ROUSSEAU,J. (1991). El contrato social. Madrid: Espasa-Calpe.

SHAFER, B. (1972). Faces of nationalism: New realities and old myths. New York: Harcourt Brace Jovanovich. SVAMPA, M. (2017). El concepto de crisis en reinhart Koselleck. Polisemias de una categoría histórica. Revista Teoría y Filosofía Política Clásica y Moderna, 131.

VELÁSQUEZ SILVA, D. (2010). Mutaciones del concepto patria, Perú. 1730-1866. Lima: Universidad Mayor de San Marcos.

\section{Páginas web consultadas}

http://www.bdigital.unal.edu.co/25/1/constitucion_de_cundinamarca_1811.pdf

http://www.bdigital.unal.edu.co/9566/1/59835941.2013.pdf

http://www.cervantesvirtual.com/portales/constituciones_hispanoamericanas/obra visor/constitucion-federalde-los-estados-de-venezuela-21-de-diciembre1811/html/86de8dbc-4b14-4131-a616-

9a65e65e856a_2.html\#I_30_.

http://www.cervantesvirtual.com/obra/proyecto-de-decreto-sobre-restablecimiento-y convocatoria-de-corteso-consulta-al-pais-13-de-mayo-de-1809--0/.

http://www.derecho.uba.ar/revistas-digitales/index.php/revista-electronica gioja/article/view/47.

https://doi.org/10.25057/issn.2145-2776.

http://www.lhistoire.fr/doit-r\%C3\%A9habiliter-robespierre.

http://secuencia.mora.edu.mx/index.php/Secuencia/rt/printerFriendly/1464/1693.

http://web.frl.es/DA.html.

Trabalho enviado em 04 de fevereiro de 2018.

Aceito em 21 de março de 2018. 